\title{
Técnica, tecnologia e educação em Heidegger e Simondon
}

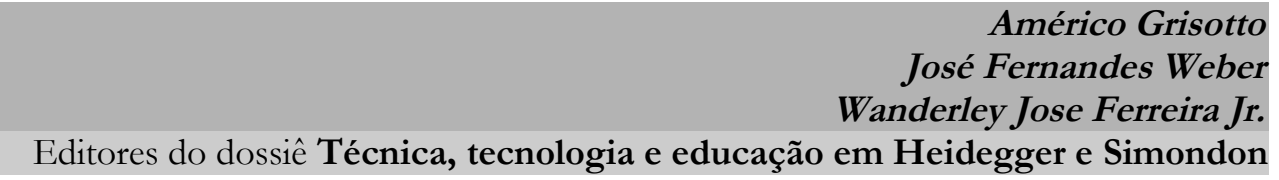

$\mathrm{D}$ esde o início do século $X X$ a técnica constituiu-se num dos temas de maior apelo à reflexão filosófica, mas não apenas à filosofia, pois há muito se percebeu que no destino da técnica joga-se um jogo no qual tudo e todos estão implicados, em que, dada sua abrangência e suas implicações, a própria divisão das áreas do conhecimento torna-se inoperante, pois a técnica preside uma voragem que tudo aglutina. O que há de comum entre a eficiência nas técnicas de transplante de órgãos; o implemento da produtividade no cultivo de batatas; a ampliação do conhecimento sobre as dimensões espaciais do cosmos; a constituição de uma realidade virtual que possibilita a criação de uma rede de relações com outros entes, reais ou virtuais, cuja presença física (material) possui a realidade da imagem; os dilemas éticos resultantes da exploração dos recursos naturais do planeta, a tal ponto intensos, que ameaçam a continuidade da vida natural; o desenvolvimento de objetos que tornam a vida mais confortável, e a instauração de um modo de considerar a vida em que se acredita que os dilemas resultantes do nosso modo de ser no mundo, enfim, estão em vias de serem resolvidos? O que há de comum entre eventos a princípio tão díspares é que a sua efetividade, a sua "realidade", é mediada pela técnica. Outro modo de dizê-lo é afirmar que sua condição de possibilidade está inscrita na técnica, na tecnologia, como "o caroço no fruto". Queira-se ou não, a técnica passou a constituir a mediação por meio da qual o sentido do mundo é desvelado, criado. 
Hoje as relações entre os homens, o trabalho e a própria inteligência dependem da metamorfose incessante de dispositivos técnicos de todos os tipos. A escrita, a leitura, a visão, a audição, a criação e a aprendizagem são capturados por uma informática cada vez mais avançada. Emerge nesse início do século XXI um conhecimento por simulação que ainda não foi inventariado. A técnica toma parte ativa nas formas de pensar, conhecer e sentir que determinam o modo de ser do homem contemporâneo. É através dos artefatos técnicos, como o computador, que estruturamos nossa experiência de um mundo cada vez mais esquadrinhado pelo cálculo. Se, desse modo, as condições de possibilidade do sentido do mundo estão inscritas no âmbito de vigência da técnica, desnecessário será insistir no fato de que também a educação é afetada por essa dinâmica planetária da técnica. Com tal afirmação não se pretende apenas dizer que, em virtude disso, a escola inevitavelmente passou a incorporar às suas práticas o uso dos objetos tecnológicos; isso seria minimizar, até à indigência, a efetiva extensão do problema em foco. Primeiro, porque seria o caso de compreender educação como um campo de abrangência mais amplo do que aquele configurado pela educação escolar. A palavra "escola" não diz tudo aquilo que a educação pode significar. O que interessa perceber é que a técnica, a tecnologia configuram modos de constituição do humano, que gradativa e intensivamente ocupam o espaço vacante resultante da crise do humanismo. E a crise do humanismo, no século XX, representa, no âmbito espiritual, aquilo que a crise da escola representa no âmbito institucional. Em segundo lugar, porque é necessário perceber que uma mera defesa ou crítica da técnica, da tecnologia, seja num sentido geral, seja num sentido particular - por exemplo, da vigência da tecnologia no quotidiano ou na 
educação, que não atinge o plano da apreensão da essência da técnica -, erra o foco desde o início. Não dizia Martin Heidegger, em A questão da técnica, que "a essência da técnica não é nada de técnico"? E Simondon, em Sobre o modo de existência dos objetos técnicos, não advertia que "possuir uma máquina não é conhecê-la"? Assim, será fundamental apreender o que é a técnica e, conjuntamente a isso, se precaver da tentação de pensá-la a partir do registro do mero uso.

Quem se propõe a retomar o modo como, pelo menos desde o fim do século XIX, a reflexão sobre a técnica adentrou nos domínios do pensamento filosófico, deparar-se-á com uma clara demarcação: até a década de 50 do século passado, a reflexão sobre a técnica era marcadamente crítica. Destacava-se o poder destruidor, encobridor da técnica, na medida em que, segundo tal modo de conceber, no espírito da técnica, residia um poder desertificador do mundo, a ponto de criar uma via unilateral, e por isso mesmo destruidora da complexidade inerente à constituição do sentido do mundo. O autor em que tais pensamentos atingem uma posição paradigmática é Martin Heidegger. Contudo, como o próprio Heidegger afirma no já citado escrito A questão da técnica, "não há uma demonia da técnica". Se a técnica torna-se digna de questionamento é porque pretende-se "preparar um relacionamento livre com a técnica". E isso somente se dará ao buscar-se-lhe a essência. Após a década de 50 do século passado, ocorreu uma mudança significativa no juízo sobre a técnica e a tecnologia, de modo que, a partir de então, passou-se a considerar a técnica como um modo próprio da humanidade, constitutivo do sentido de ser no mundo, sem cuja consideração nenhuma caracterização do humano lograria alcançar inteligibilidade. $\mathrm{O}$ autor em que tais considerações alcançam o ponto 
de maturação é Gilbert Simondon. Para o autor francês, é falsa e sem fundamento a oposição entre a cultura e a técnica, entre o homem e a máquina, pois os objetos técnicos são os mediadores entre o homem e a natureza.

Os artigos deste dossiê buscam pensar, tendo em vista as delimitações e as referências específicas adotadas, tanto os modos como Heidegger e Simondon pensam a técnica, a tecnologia, quanto os vínculos entre técnica, tecnologia e educação. Sendo a técnica, ora um modo próprio do desencobrimento, como em Heidegger, ora a mediação entre homem e natureza, como em Simondon, em ambos os casos a educação, naquele sentido amplo acima apontado, lhe diz respeito de um modo essencial. Por essa razão, para se compreender o que está em jogo no âmbito de vigência da técnica, torna-se imperativo abandonar a concepção segundo a qual as fronteiras possuem apenas a função de separar territórios. E isso pelo simples fato de que, em questões de geografia do pensamento, uma fronteira não apenas separa territórios, mas também une-os, inapelavelmente.

Os primeiros cinco artigos do dossie $\hat{e}^{1}$ são dedicados ao pensamento de Martin Heidegger.

Em A provocação dos aparatos tecnológicos, Celso R. Braida busca mostrar que a situação humana no mundo dos aparatos maquínicos e das formas tecnológicas de relação e subsistência exige uma revisão da autocompreensão humanista, pois se a tecnologia moderna estabelece uma ruptura com os modos de vida milenares baseados em artefatos pré-científicos, isso não implica uma perda ou destruição da essência natural e humana.

\footnotetext{
${ }^{1}$ A apresentação dos artigos do dossiê vale-se dos resumos formulados pelos autores, acompanhando de perto os termos por eles empregados.
} 
Gerson Brea, no artigo Sobre a possibilidade de uma filosofia da técnica correta e verdadeira, pretende aproximar-se do fenômeno da técnica, a partir de uma discussão do texto A questão da técnica, de Martin Heidegger. Após uma breve introdução que apresenta diversos momentos de concepções antropológicas da técnica, analisa passagens centrais da proposta heideggeriana em que a essência da técnica é compreendida como um acontecimento da verdade.

Em Heidegger, técnica e educação: uma meditação histórico-ontológica, Marcos Aurélio Fernandes segue as indicações do pensamento meditativo de Heidegger, questionando o sentido histórico-ontológico da técnica e investigando seus fundamentos metafísicos: a técnica é o fim da era metafísica, não só no sentido de término, mas também de plenitude de realização e transformação, acenando para outro princípio do pensar no porvir e, por conseguinte, um outro modo de o homem habitar a terra e uma outra configuração essencial da educação.

Wanderley Jose Ferreira Jr., em Técnica e educação em tempos de indigência, procura refletir sobre as possíveis articulações entre técnica e educação no âmbito do pensamento heideggeriano. Tomando como ponto de partida os possíveis limites da analítica existencial de Ser e Tempo no que respeita a questionar o fenômeno da técnica moderna, explicita como a questão da técnica articula-se com a questão da formação humana no Discurso de Reitorado (A autoafirmação da universidade alemã) (1933). Caracteriza a essência da técnica moderna na fase terminal da metafísica indicando em que sentido vivemos um estado de indigência e penúria, impotentes para pensar.

Em Destruição da história da educação: indicações programáticas a partir da hermenêutica heideggeriana, Roberto Saraiva Kahlmeyer-Mertens propõe 
responder o seguinte problema: como a hermenêutica fenomenológica de Heidegger possibilita pensar os conceitos fundamentais da educação?. Para responder essa pergunta, o autor apresenta o projeto heideggeriano da hermenêutica da facticidade, caracterizando a história da educação como narrativa dos seus fundamentos e indicando como a hermenêutica heideggeriana liberaria o sentido das interpretações de educação e tornaria seus fundamentos compreensíveis.

Os artigos sobre o pensamento de Gilbert Simondon constituem a segunda parte do presente dossiê. O próprio filósofo, em tradução assinada por Américo Grisotto e Laura Brandini, comparece com Mentalidade técnica, texto no qual mostra que existe uma mentalidade técnica que em desenvolvimento, portanto incompleta e correndo o risco de ser prematuramente considerada monstruosa e desequilibrada. Ela necessita de uma atitude preliminar de generosidade em relação à ordem de realidade que procura manifestar, pois essa gênese incompleta coloca em jogo valores que uma recusa global poderia desconhecer e correria o risco de eliminar. Do ponto de vista de Simondon, a mentalidade técnica é coerente, positiva, fecunda na área dos esquemas cognitivos, incompleta e em conflito consigo mesma, pois é ainda mal definida no quadro das categorias afetivas, enfim sem unidade e quase inteiramente a ser construída na ordem do desejo.

No artigo O Corpo Social do Sujeito, traduzido por Marcos Nalli, José Fernandes Weber e Américo Grisotto, Xavier Guchet afirma que Simondon situou o conjunto de seus trabalhos sob o signo de uma confrontação entre a filosofia e as ciências humanas. Partindo da constatação de que as ciências humanas de sua época são insuficientemente unificadas e que elas perdem a 
realidade do homem concreto e completo, quer propor uma filosofia da individuação humana que possa renovar os saberes sobre o homem. Essa filosofia da individuação se apresenta como um esforço para casar duas dimensões da realidade humana que são habitualmente tratadas separadamente: as formas de organização social de um lado, os modos de confrontação à matéria do outro - em suma, o social e o técnico. Simondon lançaria, dessa forma, a possibilidade de propor um novo humanismo, à altura dos desafios contemporâneos.

Em Individuar, nos individuar e individuar em nós: a transindividualidade do conhecer, Luis Eduardo Ponciano Aragon propõe uma leitura da obra de Simondon com ênfase no conceito de transindividual, discriminando nesse percurso elementos da ética e do processo do conhecimento no pensamento do autor.

Para Rainer Maria Brito, autor de As escalas, o hiato e a circunstância técnica, há uma descontinuidade entre os enunciados acerca da circunstância técnica e os recursos que a constituem como matéria; mas será esta descontinuidade apreensível sob nome de "técnica"? Talvez não, o que indicaria a necessidade de desviar da "técnica" desviar. Assim teria feito o Simodon dos cursos ministrados entre 1960-70, que exibiam estreitos exercícios textuais analítico-descritivos de algumas circunstâncias técnicas específicas.

No artigo Tecno-estética e formação: especulações iniciais a partir de Simondon e Buckminster-Fuller, Emerson Freire sustenta que dois pensadores, cada qual à sua maneira, incorporaram sempre em suas reflexões a técnica enquanto componente primordial de seus trabalhos: o inventor norte-americano Richard Buckminster Fuller e o filósofo francês Gilbert Simondon. Ambos têm 
ressonâncias na forma de pensar a tecnologia em relação ao social e na maneira de conceber o processo inventivo: para ambos, técnica e estética não estão em contraposição ou separadas, muito menos são componentes hierarquicamente inferiores do conhecimento.

Guilherme Flynn Paciornik e Pedro Peixoto Ferreira, no artigo Cleodon Silva e a Casa dos Meninos: mecanologia, do reco-reco à internet, narram o encontro feliz das trajetórias do ativista Cleodon Silva com a instituição Casa dos Meninos, descrevendo como esse encontro pode ajudar a repensar o papel daquilo que Simondon chamou de "mecanólogo" ou "tecnólogo": aquele que estuda os indivíduos técnicos completos, que introduz na cultura "a consciência da natureza das máquinas, de suas relações mútuas e de suas relações com o homem, e dos valores implicados nestas relações".

O último artigo do dossiê, Ser Humano na Era da Reprodutibilidade Técnica, de Marcos Alexandre Gomes Nalli e José Fernandes Weber, apresenta algumas possibilidades de reflexão que permitam articular o homem, sua natureza, e o advento das novas tecnologias. De acordo com os autores, as novas tecnologias - a biotecnologia, a genética, a nanotecnologia e as ciências informacionais parecem convergir no sentido de forçar a se repensar a própria natureza humana, de modo a se tomá-la também como uma espécie de artefato.

Desejamos a todos uma boa leitura, fazendo votos de que, para os estudiosos e iniciados, o presente dossiê propicie um pertinente e competente aprofundamento da reflexão sobre os temas abordados, assim como, para os que despertam para a temática e seus problemas, uma produtiva oportunidade de tomar conhecimento dos pontos de vista aqui expostos. 